\section{Night sweats as a manifestation of gastroesophageal reflux disease}

\author{
Alexei Berdnikov MD Stacy McPhee MD CCFP \\ Lisa LaBine MSc Tunji Fatoye MD CCFP FCFP
}

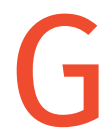

astroesophageal reflux disease (GERD) is a common condition in which gastric contents flow retrograde past the lower esophageal sphincter causing irritation and damage to the esophagus. Common symptoms associated with this disease include heartburn, chest pain, vomiting, and a hoarse voice. In most cases, some permutation of these symptoms is enough to make the diagnosis, and resolution of symptoms with acid suppression therapy strengthens the diagnostic probability. ${ }^{1}$ Despite the unusual association between night sweats and GERD, this case report contributes to the literature underscoring the importance of considering GERD in the diagnostic workup for night sweats. Currently, there is very little evidence to support GERD as a cause of night sweats, with previous associations between GERD and night sweats based mostly on informal observations.

\section{Case}

A 35-year-old man presented to a primary care clinic with a 3-month history of progressively worsening drenching night sweats. On history, the patient denied any systemic manifestations of malignancy including weight loss, change in appetite, fever, chills, fatigue, and lethargy. He denied any intravenous drug use or risky sexual behaviour. He is a lifelong non-smoker and has had minimal exposure to second-hand smoke. The patient denied travel to areas that are endemic to granulomatous or parasitic diseases. He consumes alcohol occasionally, drinking 1 to 2 beers per week. A review of systems revealed a 6-month history of progressively worsening moderate to severe heartburn that has never been addressed. He described his heartburn as a retrosternal burning sensation that is usually worst in the mornings. He described that his heartburn persists throughout the day and has not tried any management strategies. He further described that his sleep has been negatively affected by having to change his bedding each morning and often in the middle of the night.

Past medical history included obstructive sleep apnea treated with continuous positive airway pressure, previous right cholesteatoma, and cholecystectomy. He does not take any medication. The patient's family history was unremarkable for any malignant or hereditary diseases. The patient's childhood vaccinations were up-to-date and he had no allergies.

Findings of physical examination of his cardiovascular and respiratory systems were unremarkable. Further examination of his lymphatic system, abdomen, rectum, and head and neck did not yield any positive findings. His weight remained stable at $128 \mathrm{~kg}$. Vital signs included a blood pressure of 135/80 mm Hg; his heart rate was regular at 65 beats/min; his oxygen saturation was 98\%; and his respiratory rate was 16 breaths/min.

Risks and benefits of advanced contrast imaging were discussed with the patient. A decision to first treat his heartburn in hopes of also alleviating his night sweats was made. Omeprazole therapy was started and the patient was asked to return to clinic in 1 month. Upon return to clinic, the patient indicated complete resolution of drenching night sweats. On reassessment, the patient did not describe any symptoms of malignancy or

\section{Editor's key points}

- Despite the unusual association between night sweats and gastroesophageal reflux disease (GERD), this case report contributes to the literature underscoring the importance of considering GERD in the diagnostic workup for night sweats.

- This case provides an interesting and rare manifestation of GERD, highlighting the importance of maintaining a broad differential diagnosis, taking a detailed patient history, and appropriately escalating care.

- A key learning point of this case report was the appropriate escalation of care. After discussion and shared decision making with the patient, it was deemed unnecessary to pursue advanced diagnostic imaging.

\section{Points de repère du rédacteur}

- Malgré l'association inhabituelle entre les sueurs nocturnes et le reflux gastro-œsophagien pathologique (RGO), ce rapport de cas contribue à la littérature scientifique qui souligne l'importance d'envisager le RGO dans l'investigation diagnostique des sueurs nocturnes.

- Ce cas présente une manifestation rare et intéressante du RGO, et met en évidence l'importance d'un large diagnostic différentiel, d'une anamnèse détaillée du patient et d'une croissance appropriée des soins.

- La croissance appropriée des soins constitue un élément d'apprentissage clé à tirer de ce rapport de cas. Après une discussion et une prise de décision partagée avec le patient, il a été jugé inutile de poursuivre avec l'imagerie diagnostique avancée. 
infection. The risks and benefits of advanced contrast imaging were again discussed and the shared decision to defer imaging and instead continue monitoring for symptoms suggestive of underlying malignancy or infection was made. After 3 months of proton pump inhibitor use the patient continued to describe complete resolution of night sweats and heartburn. Based on clinical grounds, the diagnosis of GERD was made and deemed to be the cause of the patient's night sweats.

The patient's workup included complete blood count; liver function tests; measurement of electrolyte, liver enzyme, thyroid stimulating hormone, and hemoglobin $\mathrm{A}_{1 \mathrm{c}}$ levels; a Mantoux test; hepatitis A, B, and $C$ serology; and a sexually transmitted infection panel and HIV serology. Findings of all investigations were unremarkable. There were no abnormal findings on chest x-ray scan. The patient's weight was closely monitored for 3 months and remained stable. Vital signs remained within normal limits at all visits.

\section{Discussion and conclusion}

This case describes an interesting and rare manifestation of GERD, highlighting the importance of maintaining a broad differential diagnosis when considering night

Table 1. Potential causes of night sweats

\begin{tabular}{|c|c|}
\hline CATEGORY & POTENTIAL CAUSES \\
\hline \multirow[t]{2}{*}{ Malignancy } & Lymphoma \\
\hline & Solid tumours \\
\hline \multirow[t]{4}{*}{ Infections } & Tuberculosis \\
\hline & Brucellosis \\
\hline & Bacterial infections \\
\hline & HIV \\
\hline Medications & See Table 2 \\
\hline \multirow[t]{3}{*}{ Withdrawal symptoms } & Alcohol \\
\hline & Opioids \\
\hline & Cocaine \\
\hline \multirow[t]{3}{*}{ Endocrine disorders } & Pheochromocytoma \\
\hline & Carcinoid syndrome \\
\hline & Hyperthyroidism \\
\hline \multirow[t]{2}{*}{ Neurologic disorders } & Autonomic dysreflexia \\
\hline & Syringomyelia \\
\hline \multirow[t]{6}{*}{ Other } & Menopause \\
\hline & Idiopathic hyperhidrosis \\
\hline & Sleep apnea \\
\hline & Gastroesophageal reflux disease \\
\hline & Diabetes insipidus \\
\hline & Temporal arteritis \\
\hline
\end{tabular}

sweats, taking a detailed patient history, and appropriately escalating care.

The association between night sweats and GERD is seldom described in the literature. To the best of our knowledge, literature surrounding night sweats as a symptom of GERD stems from a letter by Reynolds in 1989 in the Journal of Clinical Gastroenterology. ${ }^{2}$ Through observation, Reynolds identified 36 patients in his practice with night sweats due entirely to reflux. ${ }^{3}$ Since that, only 2 published case reports have described this phenomenon. Betancor et al (2002) and Young et al (2007) describe cases in which, after ruling out other causes, night sweats were eliminated with the use of antireflux treatment. 4,5

A diagnosis of GERD often relies on the elimination of symptoms after initiation of acid suppression therapy. This case report outlines a similar systematic approach used in previous case reports to diagnose acid reflux as the cause of night sweats. Alongside earlier literature, this case report aims to raise the awareness of gastroesophageal reflux as a realistic cause of night sweats. However, there are no

Table 2. Medications associated with night sweats

\begin{tabular}{|c|c|}
\hline CATEGORY & MEDICATION \\
\hline \multirow[t]{5}{*}{ Antidepressants } & Selective serotonin reuptake inhibitors \\
\hline & Venlafaxine \\
\hline & Bupropion \\
\hline & Tricyclic antidepressants \\
\hline & Clozapine \\
\hline \multirow[t]{3}{*}{ Antipyretics } & Acetaminophen \\
\hline & Acetylsalicylic acid \\
\hline & Nonsteroidal anti-inflammatory drugs \\
\hline \multirow[t]{2}{*}{ Cholinergic agents } & Pilocarpine \\
\hline & Bethanechol \\
\hline \multirow[t]{2}{*}{ Hypoglycemic agents } & Insulin \\
\hline & Sulfonylureas \\
\hline \multirow[t]{3}{*}{ Hormonal agents } & Antiestrogen drugs \\
\hline & $\begin{array}{l}\text { Selective estrogen receptor } \\
\text { modulators }\end{array}$ \\
\hline & Androgen receptor blockers \\
\hline \multirow[t]{9}{*}{ Others } & Niacin \\
\hline & Sildenafil \\
\hline & Hydralazine \\
\hline & Nitroglycerin \\
\hline & Bromocriptine \\
\hline & Alcohol \\
\hline & Triptans \\
\hline & $\beta$-Blockers \\
\hline & Calcium \\
\hline
\end{tabular}


formal trials linking night sweats to GERD, which underscores the importance of clinicians reporting this rare finding. Currently, clinicians must rely on clinical judgment and minimal evidence when linking night sweats to GERD.

A key learning point of this case report was the appropriate escalation of care. After discussion and shared decision making with the patient, it was deemed unnecessary to pursue advanced diagnostic imaging. Night sweats secondary to malignancy would be unlikely to resolve after initiation of a proton pump inhibitor, which added to the resolve that advanced imaging was unnecessary. After the 3-month follow-up, the patient continued to be symptom free. By making the decision to not pursue a computed tomography scan, we effectively prevented $17 \mathrm{mSv}$ of unnecessary radiation exposure. ${ }^{6}$

There are many reasons why drenching night sweats develop (Tables $\mathbf{1}$ and 2). ${ }^{7}$ It is the duty of clinicians to thoroughly investigate this symptom, even if more common causes have been ruled out. Although still underrepresented, night sweats appear to be gaining some attention as a recognized symptom of GERD; however, further research is necessary. Our hope is that this case report helps clinicians further delineate causes of night sweats and shed light on this rare but fascinating symptom of GERD.
Dr Berdnikov is an emergency medicine resident, Dr McPhee is a family physician, Ms LaBine is a research project consultant and facilitator, and Dr Fatoye is Assistant Professor, all in the Department of Family Medicine at the University of Manitoba in Winnipeg.

Competing interests

None declared

Correspondence

Dr Alexei Berdnikov; e-mail umberdni@myumanitoba.ca

References

1. Sugerman GT. JAMA patient page. Gastroesophageal reflux disease. JAMA 2014;311(23):2452.

2. Reynolds WA. Are night sweats a sign of esophageal reflux? J Clin Gastroenterol 1989;11(5):590-1.

3. Viera AJ, Bond MM, Yates SW. Diagnosing night sweats. Am Fam Physician 2003;67(5):1019-24

4. Betancor FG, Francès Urmeneta A, Ángel-Moreno A, Pérez Arellano JL. Sudoración nocturna sin fiebre. Piense en reflujo gastroesofágico. Rev Clin Esp 2002;202:43-6.

5. Young P, Finn BC, Bruetman JE, Trimarchi H. Gastroesophageal reflux as a cause of night sweating [article in Spanish]. An Med Interna 2007;24(6):285-8.

6. Lin EC. Radiation risk from medical imaging. Mayo Clin Proc 2010;85(12):1142-6.

7. Smetana GW, Aronson MD, Kunins L. Approach to the patient with night sweats. Waltham, MA: UpToDate; 2017. Available from: https://www.uptodate.com/contents/ evaluation-of-the-patient-with-night-sweats-or-generalized-hyperhidrosis. Accessed 2019 Jul 24.
This article has been peer reviewed.

Cet article a fait l'objet d'une révision par des pairs.

Can Fam Physician 2020;66:901-3. DOI: 10.46747/cfp.6612901 